\title{
A method of determining rooting depth from a terrestrial biosphere model and its impacts on the global water and carbon cycle
}

\author{
AXEL KLEIDON and MARTIN HEIMANN \\ Max-Planck-Institut für Meteorologie, Bundesstraße 55, 20146 Hamburg, Germany
}

\begin{abstract}
We outline a method of inferring rooting depth from a Terrestrial Biosphere Model by maximizing the benefit of the vegetation within the model. This corresponds to the evolutionary principle that vegetation has adapted to make best use of its local environment. We demonstrate this method with a simple coupled biosphere/soil hydrology model and find that deep rooted vegetation is predicted in most parts of the tropics. Even with a simple model like the one we use, it is possible to reproduce biome averages of observations fairly well. By using the optimized rooting depths global Annual Net Primary Production (and transpiration) increases substantially compared to a standard rooting depth of one meter, especially in tropical regions that have a dry season. The decreased river discharge due to the enhanced evaporation complies better with observations. We also found that the optimization process is primarily driven by the water deficit/surplus during the dry/wet season for humid and arid regions, respectively. Climate variability further enhances rooting depth estimates. In a sensitivity analysis where we simulate changes in the water use efficiency of the vegetation we find that vegetation with an optimized rooting depth is less vulnerable to variations in the forcing. We see the main application of this method in the modelling communities of land surface schemes of General Circulation Models and of global Terrestrial Biosphere Models. We conclude that in these models, the increased soil water storage is likely to have a significant impact on the simulated climate and the carbon budget, respectively. Also, effects of land use change like tropical deforestation are likely to be larger than previously thought.
\end{abstract}

Keywords: land use change, net primary production, optimization, rooting depth, terrestrial biosphere model, water cycle

Received 13 February 1997; revised version accepted 12 June 1997

\section{Introduction}

In the terrestrial biosphere, the depth (and the extent) of roots determine the maximum amount of water that can be stored in the soil for transpiration. Hence, rooting depth is an important parameter for large areas of the world's vegetation which are water limited during part of the year.

Land surface schemes of Atmospheric General Circulation Models (GCMs) (e.g. BATS (Dickinson et al. 1993), ECHAM (Roeckner et al. 1996), Sib2 (Sellers et al. 1996)) and models of the terrestrial biosphere (e.g. CASA (Potter et al. 1993), SILVAN (Kaduk \& Heimann 1996), TEM

Correspondence: A. Kleidon, tel + 49/40-41173-117; fax + 49/ 40-41173-298, e-mail kleidon@dkrz.de
(Raich et al. 1991)) both need rooting depth as a parameter to determine the storage size of the soil water pool. The storage capacity of the soil in turn determines how much water is available for transpiration during dry periods and thus affects the water stress of the vegetation in these periods. In present-day models, rooting depth is considered to be constant (within biomes and with respect to climatic forcing), usually not exceeding $2 \mathrm{~m}$. Little attention has been given so far to the question of how important this parameter is in the processes that determine fluxes of water and carbon between the vegetation and the atmosphere.

In contrast to the value of rooting depth used in global models, field studies show roots in some tropical regions 
going as deep as $60 \mathrm{~m}$ (Stone \& Kalisz 1991). Also, it was estimated, that large parts of the Amazonian evergreen forests depend on deep roots to maintain green canopies during the dry season (Nepstad et al. 1994). During this period, Nepstad et al. (1994) also found a constant depletion rate of deep soil water, which indicates that water uptake by roots took place at that depth and suggests that transpiration was not restricted due to lack of soil water supply. These effects have not been included into present-day global models. This is partly due to lack of knowledge about the current distribution of rooting depth, which is difficult to obtain. Increasing rooting depth within global models should lead to higher water supply and hence have a pronounced effect on the hydrological cycle and Net Primary Production (NPP) of the vegetation. Also, enhanced transpiration increases the latent heat flux into the lower atmosphere, leading to a reduced near surface air temperature and an enhanced moisture flux within GCMs (Kleidon \& Heimann 1997).

Our aim in this paper is to outline a method of how to derive a global distribution of rooting depth by using a Terrestrial Biosphere Model. We base our approach on the idea that there should be an optimum rooting depth depending mainly on soil texture and climate. This is motivated by the following reasons: on the one hand, deeper roots increase the vertical extent of the soil water storage accessible to plants, which in turn increases the ability of the vegetation to extract water. This is beneficial to the assimilation of carbon under water stress conditions. On the other hand, as roots grow deeper, more carbon needs to be allocated to the root system for construction and maintenance, which then reduces the amount of carbon available for above-ground growth and competition. With these two competing effects in mind, we may postulate that there should be an optimum rooting depth, at which the gain or survival power of the vegetation (e.g. expressed by NPP) is at a maximum.

However, costs of roots in terms of water- and nutrient uptake are mostly unknown and hence not implemented in present-day biosphere models (for one modelling approach see Kleidon \& Heimann 1996). Therefore, we choose to demonstrate the method with a model, which is nevertheless capable of simulating the mechanism described above. This model consists of a simple parameterization of NPP, depending on incoming Photosynthetically Active Radiation (PAR) and a drought stress factor. The drought stress factor is calculated by using a simple model for soil hydrology ('bucket model'). Within this model, increasing rooting depth first increases the soil water storage, but beyond a certain depth, productivity is not further increased by additional soil water storage. Thus, it is assured that there is an optimum rooting depth within this model. The model will be described in more detail below.
The model runs on a daily time step and is forced with incoming solar radiation, precipitation and atmospheric potential evapotranspiration. The forcing variables are derived from a global monthly climatology. Maximization is performed numerically by 'Golden Section Search' (Press et al. 1992). Subsequently, we compare the rooting depth distribution obtained by maximization to averages of maximum rooting depth from field studies (Canadell et al. 1996).

As a sensitivity study, we also calculate optimized rooting depths under a setup with increased water use efficiency (WUE = assimilated carbon/transpired water). This can be viewed as the vegetation response to an increase in atmospheric carbon dioxide concentration $\left(\mathrm{CO}_{2}\right)$, since the WUE is likely to increase (see, e.g., Mooney et al. 1991). We model the effect of changed WUE in two extreme ways: In the one extreme, the increase of WUE is accomplished by reduction of transpiration. In the other extreme case, carbon assimilation (i.e. NPP within the model) is increased by a reduction of water stress. In this way WUE is also changed. We show the impacts on both of these cases for the determination of optimum rooting depth and on NPP and hydrology.

\section{Methodology}

\section{Model description}

To demonstrate the method, we apply it to a simple, prognostic formulation of Net Primary Production (NPP) with a hydrological submodel. It does not contain processes like allocation, root-shoot communication, or nutrient uptake. The limitations of the model (and the method) and its consequences on the results are discussed in more detail in the discussion section below. The formulation of NPP is based on a common approach used in diagnostic studies (e.g. (Heimann \& Keeling (1989)), where NPP depends on the absorbed PAR (Photosynthetically Active Radiation) only:

$$
N P P(f P A R)=A \times f P A R \times P A R,
$$

where $A$ is the globally constant light use efficiency and FPAR is the fraction of absorbed PAR. We argue, that FPAR mainly reflects limitations or modifications of the vegetation such as water stress, nutrient stress, land use (e.g. agriculture) and temperature limitations (phenology), which do not allow the vegetation to convert all of the incoming PAR into carbon assimilates. Here, we consider water limitation only, and write NPP as

$$
N P P(D)=A \times \alpha(D) \times P A R
$$

with $\alpha(D)$ being the water stress factor, which depends in some way on the rooting depth $D$ (see below for 
details). The NPP calculated in this way could be called potential, water limited NPP.

To obtain an estimate for the water stress factor, we make use of a bucket model to simulate soil hydrology. We use the model of Prentice et al. (1993). In the following we outline the model (and its forcing) only to an extent that is necessary to understand the mechanisms described in the later sections.

The water stress factor is parameterized as

$$
\alpha(D)=\min \left[\frac{\operatorname{SUPPLY}(D)}{D E M A N D} ; 1\right],
$$

where $D E M A N D$ is the demand for transpiration from the atmosphere and SUPPLY is the soil water supply for transpiration. DEMAND is set to the 'equilibrium evapotranspiration rate' calculated fom the approach of McNaughton \& Jarvis (1983), where this rate is estimated from the energy budget. SUPPLY is calculated following Federer (1982) by:

$$
\operatorname{SUPPLY}(D)=c \times \frac{W}{W_{M A X}(D)} .
$$

Here, $c$ is the maximum soil water supply rate for transpiration, set to be $1 \mathrm{~mm} \mathrm{~h}^{-1}$ and $W$ the amount of plant available water stored within the rooting zone. Maximum plant available soil water storage $W_{M A X}$ ('bucket size') is given by

$$
W_{M A X}(D)=D \times P A W,
$$

where $P A W$ is the difference between field capacity and permanent wilting point for $1 \mathrm{~m}$ of soil, taken from a global data set (Batjes 1996).

The change of soil water $\Delta W$ in a time step $\Delta t$ is described by

$$
\Delta W=\text { PRECIP-TRANS-RUNOFF, }
$$

where PRECIP is precipitation, TRANS the transpiration and RUNOFF the runoff and the drainage from the soil column during this time step. TRANS is calculated as the minimum of supply of soil water (given by eqn 4 ) and demand for transpiration:

$$
\text { TRANS }=\min [S U P P L Y, D E M A N D] .
$$

By combination of (4) and (7) we see, that within this formulation, drought stress sets in if $W$ falls below a critical water content of $W_{\text {crit }}$ given by

$$
W_{\text {crit }}=\frac{W_{M A X} \times D E M A N D}{c} .
$$

If $W$ is greater than $W_{\text {crit }}$, transpiration is only limited by the atmospheric demand and NPP is not water-limited. RUNOFF is taken as the excess of soil water whenever $W$ exceeds the maximum soil water storage $W_{M A X}$ :

$$
\text { RUNOFF }=\max \left[0, W-W_{M A X}\right] .
$$

For simplicity, effects of snow and bare soil evaporation are neglected.

\section{Forcing of the model}

The biosphere model runs on a daily time step on a global grid with a half-degree horizontal resolution. We assume all land points to be covered by vegetation (i.e. including deserts). The model is forced by a monthly climatology of precipitation, cloudiness and air temperature of Cramer and Leemans (personal communication, updated version of Leemans \& Cramer (1991)). While precipitation is a direct forcing variable of the hydrologic submodel (PRECIP), cloudiness is used to calculate solar radiation (Linacre 1968), which together with air temperature is used to compute DEMAND (McNaughton \& Jarvis 1983). PAR is taken to be half of the incoming solar radiation. A 'weather generator' (Geng et al. 1986) in connection with a global data set of wet days (i.e. days with precipitation events) (Friend 1996) was used to simulate day-to-day variations in precipitation. Annual global NPP is set to a value of $60 \mathrm{GtC}$ for the experiment with a rooting depth of $D=1 \mathrm{~m}$ to obtain the light use efficiency constant $A$. We do this only to formulate the impacts on NPP on an absolute scale; the relative changes resulting from the optimization are independent of the value of $A$.

\section{Determination of rooting depth}

We calculate the optimum rooting depth by maximizing $N P P$ (i.e. eqn 2) with respect to $D$. The maximum is obtained numerically by 10 iterations using the 'Golden Section Search' algorithm (Press et al. 1992). During each iteration, the model runs for 10 years to damp the noise introduced by the weather generator. The 10 year mean of annual NPP is used as the maximization variable. We compare the results with a run of the model under the same setup but using a rooting depth of $1 \mathrm{~m}$.

\section{Sensitivity to increased water use efficiency}

The computation of optimum rooting depth has also been performed with an increased water use efficiency (WUE). Within the formulations used here, WUE can be expressed by

$$
\text { WUE }=\frac{N P P}{T R A N S} \propto \frac{\alpha}{\min [S U P P L Y, D E M A N D]} .
$$

The increase of WUE has been implemented in two different ways: 
- In the numerical experiment '0.5*DEMAND', WUE is increased by reduction of DEMAND by an arbitrary factor of 2

- In the numerical experiment ' $2 * \mathrm{ALPHA}^{\prime}, W U E$ is increased by inserting a factor of 2 into (3), so that it becomes

$$
\alpha(D)=\min \left[2 \times \frac{\operatorname{SUPPLY}(D)}{\operatorname{DEMAND}} ; 1\right] .
$$

In both experiments, WUE is doubled in water stressed conditions. While the first experiment has strong impacts on the water cycle because of the reduction of DEMAND, the latter experiment will affect NPP only. Both experiments could be seen as simulations of an environment of elevated atmospheric carbon dioxide concentration; in the experiment ' $0.5^{*} \mathrm{DEMAND}$ ' the stomatal conductance is affected by the elevated concentration ('downregulation') while it is not affected in the experiment '2*ALPHA'.

\section{Results}

\section{Optimum rooting depth}

The calculated rooting depths are shown in Fig. 1. A noticeable feature is that even relatively wet regions like the Amazon basin in South America or the Congo basin in central Africa show depths substantially larger than $1 \mathrm{~m}$. All desert regions show a noisy estimate - this is mainly due to the stochastic precipitation in the forcing. To assess the quality of this estimate, we calculate biome averages using a land cover data set (Wilson \& Henderson Sellers 1985) and compare it to averages of observations of maximum rooting depths (Canadell et al. 1996) in Fig. 2. The values for forested biomes are generally well reproduced, considering the high scatter of observed rooting depths even within the same biome. Rooting depth is overestimated for biomes (temperate grassland, shrubs, and tropical deciduous forest), where the vegetation might use leaf-shedding as a drought-avoidance strategy.

The simple formulation of hydrology affects the arctic regions: Since snow hydrology is not included in the bucket model, a considerable water deficit during the summer months in some arctic regions (parts of Alaska and Northern Canada) is created. This, in turn, causes the optimization process to 'create' deep roots in these regions since water availability and the maximum in irradiation are out of phase (see below for a general description of the mechanism). However, these regions are strongly affected by other limitations of root growth such as permafrost and low productivity, so that the formation of deep roots under the present climate is unlikely.

The high scatter in the observed biome averages also stresses the need for a conceptual approach rather than measured values in the field of modelling. It is important to notice, that the maximization process in fact determines the optimum plant available water storage of the soil ('bucket size', $W_{\text {MAX }}$ ). The corresponding optimum rooting depths are then calculated from $W_{M A X}$ by using (5) and a soil texture data set. This means, that the obtained values for optimum rooting depth depend on the soil texture data set, while the values of optimum $W_{M A X}$ (and the model results) are unaffected when using a different soil texture data set. This is useful, since available data sets of soil textural parameters vary substantially, e.g. Batjes (1996), Dunne \& Willmott (1996), and Webb et al. (1991).

The comparison of the calculated biome averages of optimum rooting depth to the observed averages should be taken with caution: the high scatter in the averages calculated from observations indicate that rooting depth is probably mainly driven by site specific characteristics (including the local climate) and cannot be classified on a biome level. This was also stated in Stone \& Kalisz (1991). It is also not clear whether the observed rooting depths represent plant strategies to increase water uptake capability. Therefore, a simple incorporation of this data set into the model can lead to inconsistencies within the model with the above principle of maximization of NPP. In contrast to the observations, the scatter in the biome averages calculated from the optimum rooting depths primarily reflects the differences in the climatic forcing (see also discussion below) and, to a lesser extent, variations in the soil texture.

\section{Impacts on NPP}

To investigate changes in annual Net Primary Production $(A N P P)$, we first scale the global sum of $A N P P$ for the standard model run (i.e. with a rooting depth of $1 \mathrm{~m}$ ) to $60 \mathrm{GtC} \mathrm{y}^{-1}$. The scaling constant obtained in this way is applied to all other experiments. With the use of the optimum rooting depth distribution, global NPP increased by $16 \%$ (see Table 1 ). We plotted the distribution of $A N P P$ for the standard run in Fig. 3(a). Increases in $A N P P$ caused by the use of the optimized rooting depth distribution is mainly concentrated on tropical regions that experience longer drought periods, such as eastern Brazil, large parts of Africa, India and northern Australia (see Fig. 3b). We visualize the seasonal effect of deep roots on NPP in Fig. 4 for a grid point in eastern Brazil. It is clearly seen that the seasonality in transpiration and hence in NPP is removed by the optimization process. The seasonal persistence - in contrast to the strong 


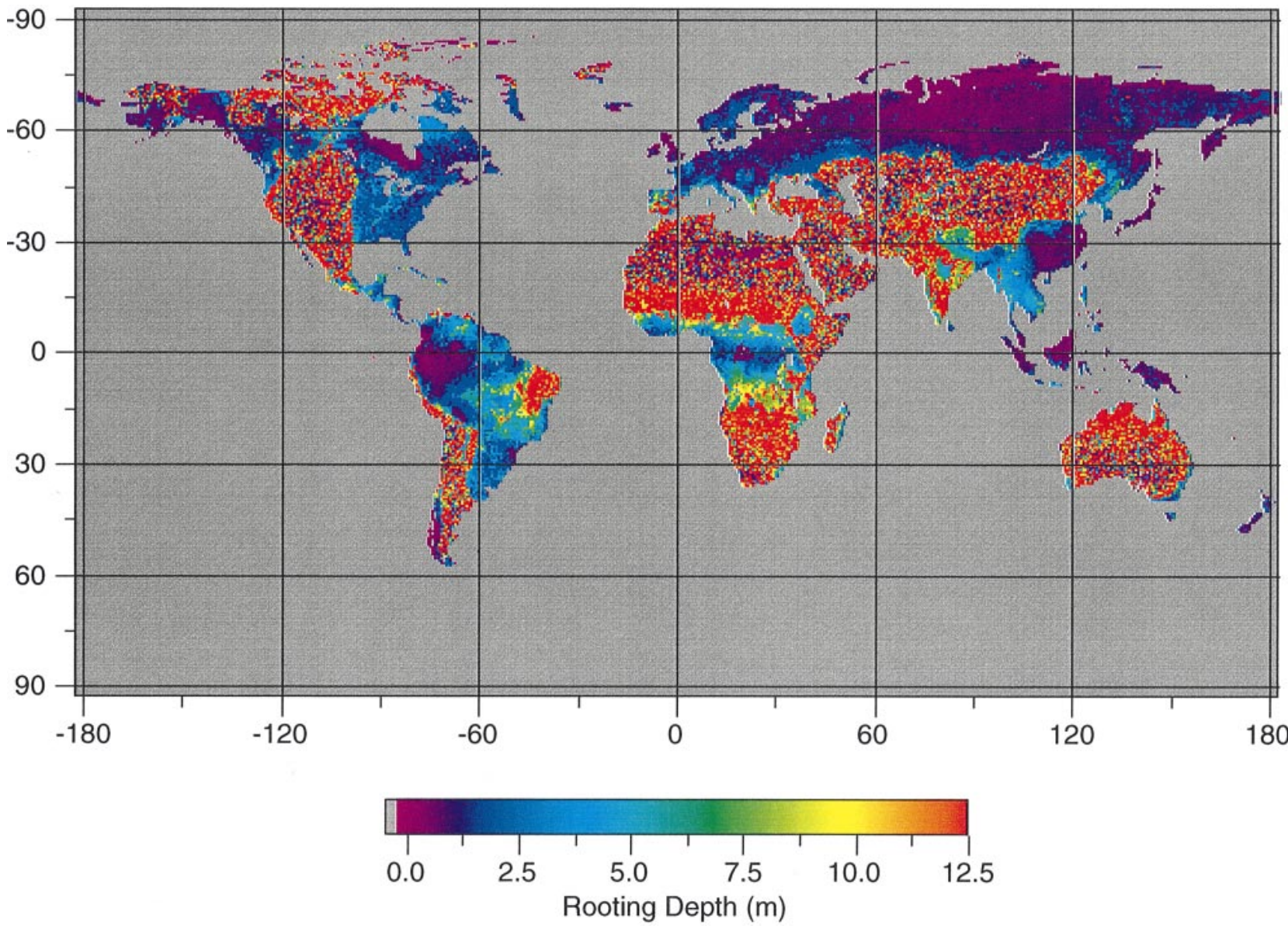

Fig. 1 Global distribution of rooting depth obtained from maximization of NPP. The scattered values in desert ecosystems is due to the stochastic precipitation generated by a weather generator.

seasonality of the meteorological forcing - has been observed by Nepstad et al. (1994) for this particular region.

\section{Impacts on watershed hydrology}

On the global scale, transpiration is increased over land areas by $18 \%$ with the use of optimized rooting depths (Table 1). The increase in transpiration shows the same spatial and temporal distribution as the change in ANPP (shown in Figs 3 and 4). Increased transpiration leads to a decreased runoff, which is also reflected in the reduction of annual river basin discharge (that is equal to the annual sum of runoff taken over the drainage basin). In Fig. 5 we show the annual river basin discharge resulting from uniform $(D=1 \mathrm{~m})$ and optimized rooting depth for 11 drainage basins that show the largest changes in runoff. For all river basins shown, discharge is reduced substantially and the resulting calculated discharge compares much better with observations (Dümenil et al. 1993). Here, again, the comparison to observations have to be taken with caution, since the model does not include several effects (such as swamps in river basins, e.g. Niger and Nile, irrigation of land, and dams) that modify the water budget of drainage basins.

\section{Mechanism behind the optimization process}

We have already shown one aspect of the effects on the seasonality in water availability at one site in Fig. 4 . This effect can be generalized by considering the water budget of regions with dry periods:

We consider humid regions first, i.e. regions that have a balanced water budget on an annual scale. These regions are characterized by the property that annual PET (potential evapotranspiration, taken to be equal to $D E M A N D$ ) is less or equal to annual PRECIP (precipitation):

$$
\int_{\text {year }} P E T d t \leqslant \int_{\text {year }} \text { PRECIP } d t .
$$

For grid points that meet this criterion, we calculate the water deficit of the dry period by integrating monthly 


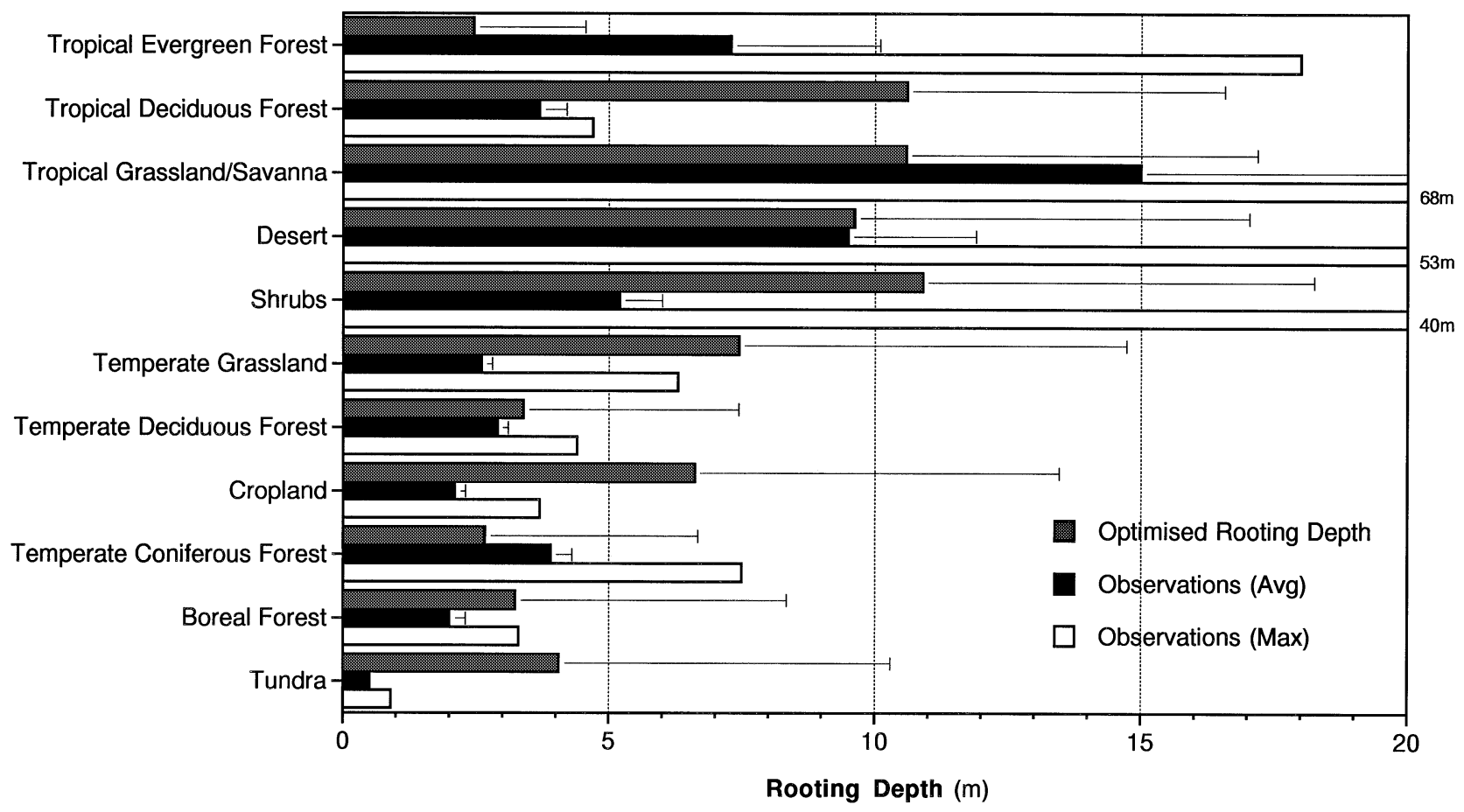

Fig. 2 Comparison of biome averages of optimum rooting depth obtained by the described method to biome averages of rooting depth and maximum rooting depth found in each biome (Canadell et al. 1996). Error bars indicate 1 SD.

Table 1 Global average of rooting depth, global annual Net Primary Production (NPP), and global averages of evapotranspiration, and runoff for the different runs. Global NPP has been set to $60.0 \mathrm{GtC} \mathrm{y}^{-1}$ for the standard case and a rooting depth of $1 \mathrm{~m}$. The scaling constant (light use efficiency) obtained in this way was used by the other experiments to calculate global annual NPP. Averages are weighted by area.

\begin{tabular}{|c|c|c|c|c|}
\hline Experiment & $\begin{array}{l}\text { Rooting depth } \\
\text { (m) }\end{array}$ & $\mathrm{NPP}\left(\mathrm{GtC} \mathrm{y}^{-1}\right)$ & $\begin{array}{l}\text { Evapotranspiration } \\
\left(\mathrm{mm} \mathrm{d}^{-1}\right)\end{array}$ & $\begin{array}{l}\text { Runoff and drainage } \\
\left(\mathrm{mm} \mathrm{d}^{-1}\right)\end{array}$ \\
\hline \multicolumn{5}{|c|}{ Standard WUE } \\
\hline Standard & 1.00 & 60.0 & 0.99 & 1.15 \\
\hline Optimized & 6.91 & 69.6 & 1.17 & 0.97 \\
\hline \multicolumn{5}{|c|}{$\begin{array}{l}\text { Increased WUE } \\
‘ 0.5^{*} \text { DEMAND' }\end{array}$} \\
\hline Standard & 1.00 & 72.8 & 0.61 & 1.53 \\
\hline Optimized & 4.33 & 80.6 & 0.69 & 1.45 \\
\hline \multicolumn{5}{|c|}{$\begin{array}{l}\text { Increased WUE } \\
2^{*} \text { ALPHA' }^{\prime}\end{array}$} \\
\hline Standard & 1.00 & 63.0 & 0.99 & 1.15 \\
\hline Optimized & 9.36 & 76.9 & 1.17 & 0.97 \\
\hline
\end{tabular}

means of PET - PRECIP for months where PETPRECIP > 0:

$$
\text { DEFICIT }=\int_{P E T>P R E C I P}(P E T-P R E C I P) d t .
$$

In Fig. 6(a) we depict the optimized soil water storage (bucket size) against the water deficit of humid regions. The bucket sizes for the case of a rooting depth of 1 meter ranges from $30 \mathrm{~mm}$ to $350 \mathrm{~mm}$ for organic soils with an average value of $72 \mathrm{~mm}$. One can clearly see in Fig. 6(a) that the optimization process creates bucket sizes that are at least as large as the water deficit. This enables the vegetation to transpire at potential transpiration rates, implying, that drought stress is eliminated. More formally speaking, all points lie above the line DEFICIT $=W_{M A X}$. There are two reasons, why the points do not lie exactly 
(a)

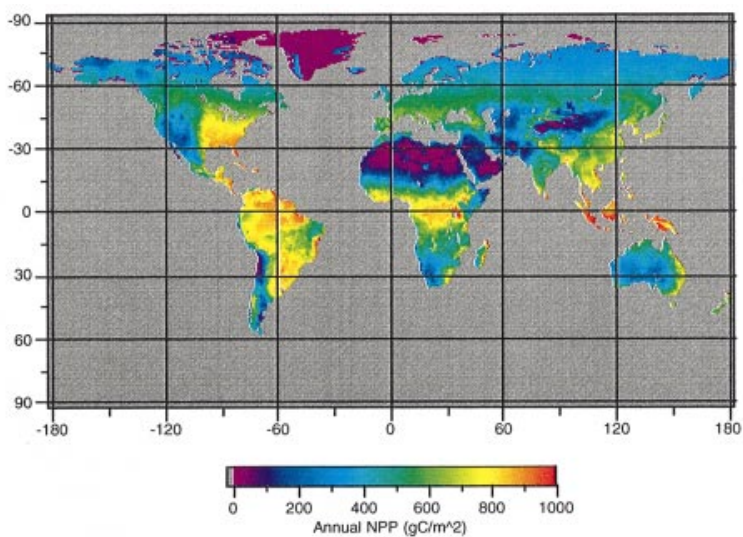

(c)

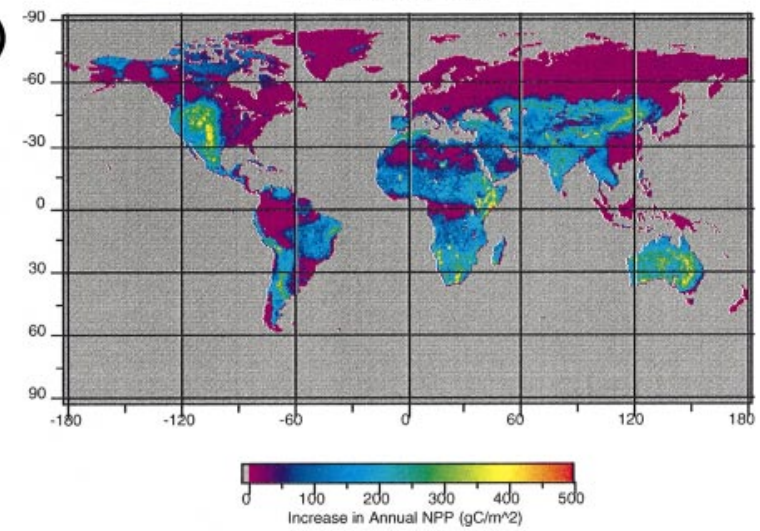

(b)

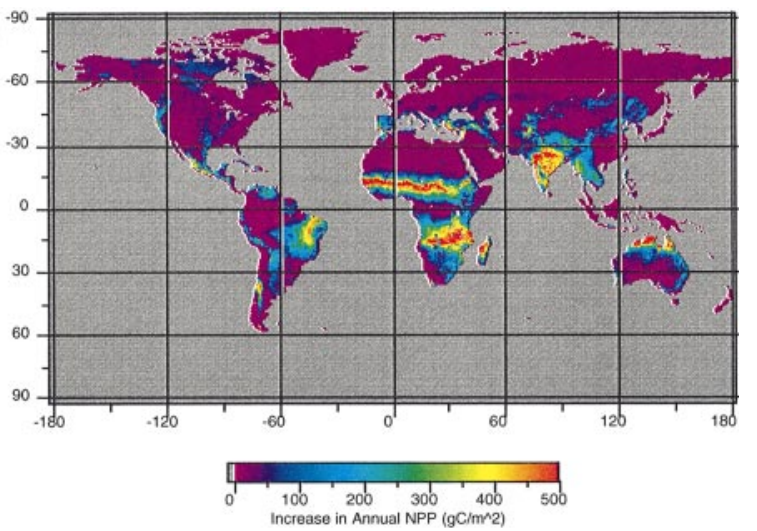

(d)

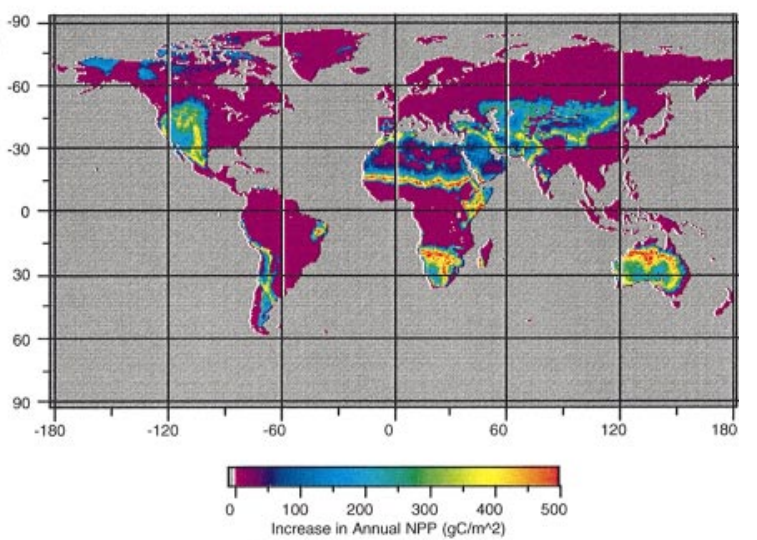

Fig. 3 Distribution of mean Annual Net Primary Production (ANPP) for the standard case (rooting depth $D=1 \mathrm{~m}$ ) (a), and changes by using an optimized rooting depth distribution (b). In (c) and (d) are shown the changes of ANPP resulting from a decreased atmospheric demand (potential evapotranspiration) for the standard rooting depth and optimized rooting depth distribution, respectively. This can be interpreted as the sensitvity of the model to deceased stomatal conductance in an elevated $\mathrm{CO}_{2}$ environment. The standard case (a) was scaled to yield a global ANPP of $60 \mathrm{GtC}$.

Fig. 4 Evapotranspiration (bars) and Net Primary Production (lines) for the standard rooting depth of $1 \mathrm{~m}$ (grey/ dashed) and the optimized rooting depth (black, solid) shown for one grid point in eastern Brazil (grid point $10^{\circ} \mathrm{S}, 45^{\circ} \mathrm{W}$ ).

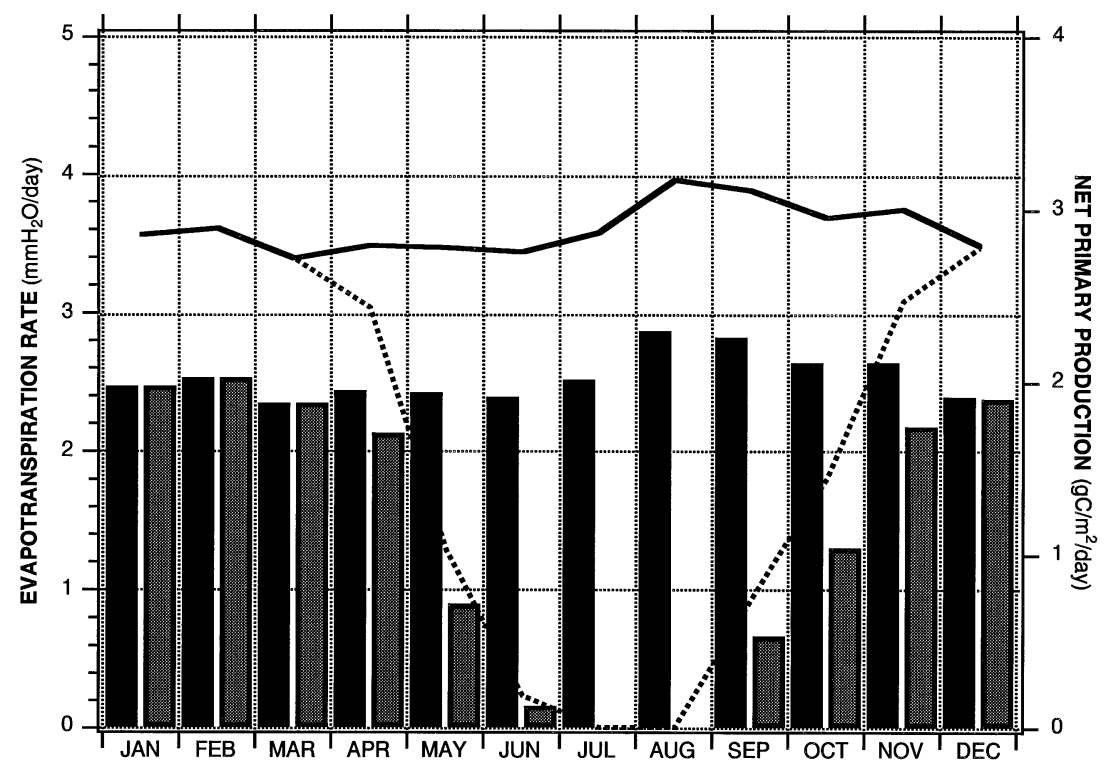

on this line: First, the water deficit calculated in the described way does not completely remove drought stress. In order to completely remove water stress, the rooting depth needs to be adjusted in such a way that $W$ never falls below $W_{\text {crit }}$ given by (8). Since $W_{\text {crit }}$ differs for each grid point (since it depends on DEMAND), we 


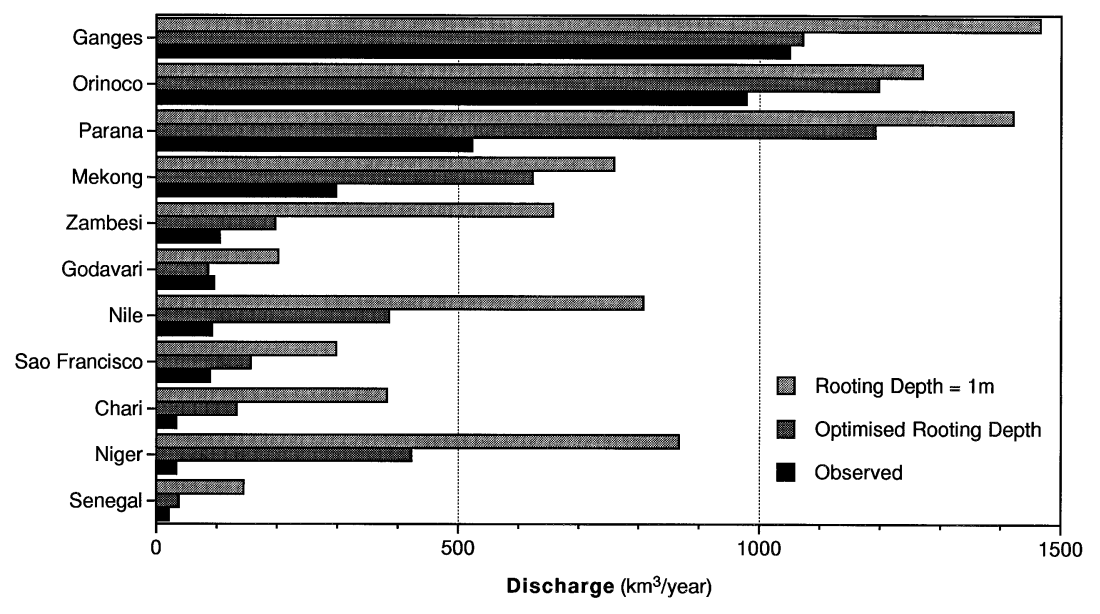

(a)
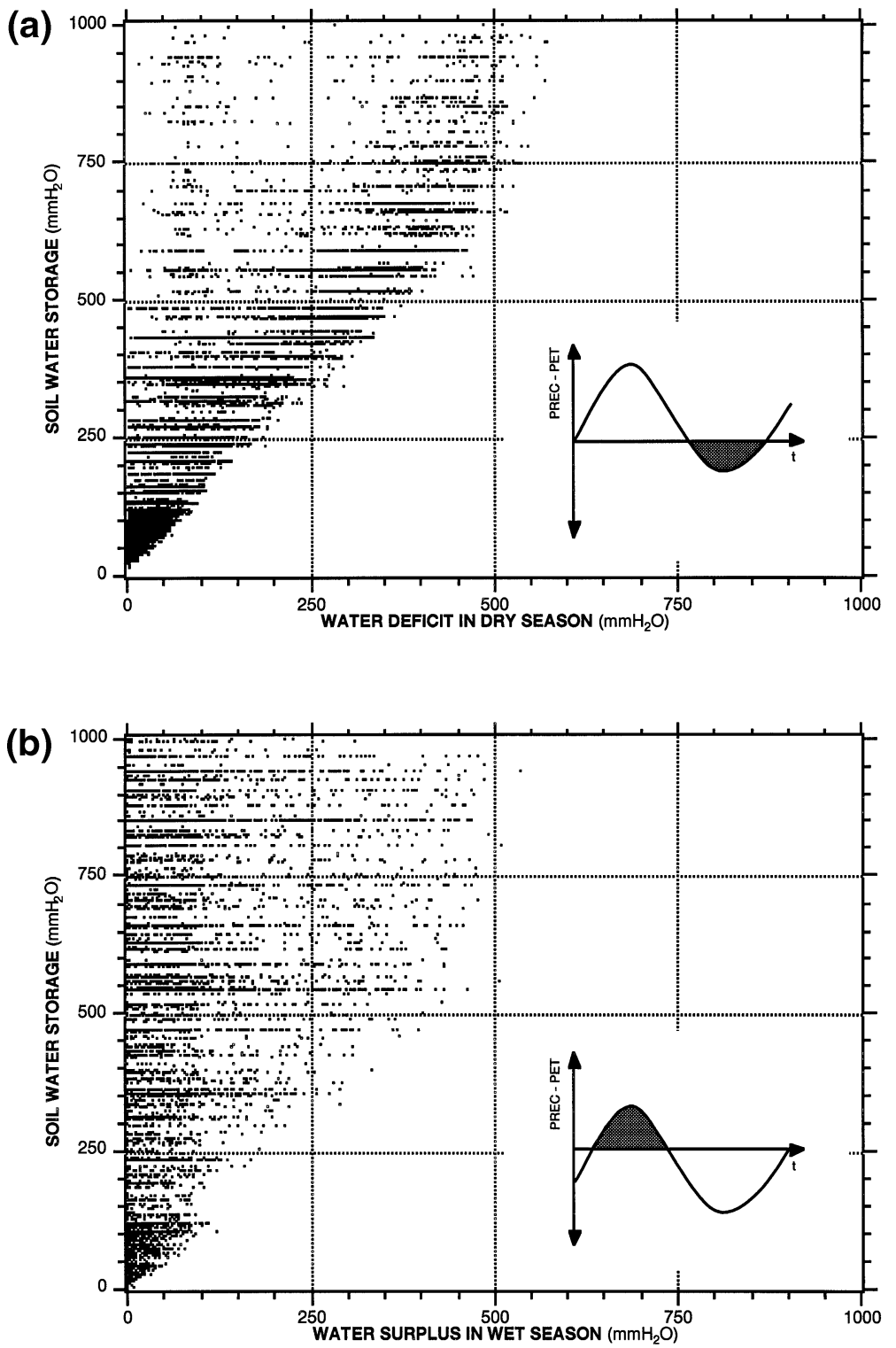

Fig. 5 Comparison of annual river basin discharge (for the standard rooting depth of $1 \mathrm{~m}$ and the optimum rooting depth) compared to observations (Dümenil et al. 1993). We selected only river basins with significant changes in runoff due to the modified rooting depth.
Fig. 6 Water deficit (for humid regions, a, see eqn 13) and water surplus (for arid regions, b, see eqn 15) plotted against optimized soil water storage. The water deficit during the dry season was calculated by integrating PET (potential evapotranspiration) - PRECIP (precipitation) during months where PET - PRE$C I P>0$ (see inlet in a). The water surplus during the wet season was calculated correspondingly by PRECIP - PET when PRECIP - PET $>0$ (see inlet in $\mathrm{b})$. 
cannot derive a general expression for a 'minimum soil water storage capacity of potential vegetation'. However, the condition DEFICIT $=W_{\text {MAX }}$ assumes a critical water content of 0 , so that this condition is a valid lower estimate. The second factor influencing the scatter of optimized bucket sizes in Fig. 6(a) is due to the stochastic precipitation. The conclusions we can draw from this is, that climate variability enhances the estimates of an optimum rooting depth and that the optimum rooting depth is mainly a result of the atmospheric forcing.

We now consider arid regions, i.e. regions where annual $P E T$ is larger than annual PRECIP:

$$
\int_{\text {year }} P E T d t>\int_{\text {year }} P R E C I P d t .
$$

For the grid points that meet this criterion, we calculate the water surplus in the wet season by integrating monthly means of PRECIP - PET for months where PRECIP - PET $>0$ :

$$
\text { SURPLUS }=\int_{P E T<P R E C I P}(P E T-P R E C I P) d t .
$$

In Fig. 6(b) we plot the optimized soil water storage (bucket size) against the water surplus of arid regions. Again, we can see that all points lie above the line SURPLUS $=W_{\text {MAX }}$. The interpretation here is slightly different to the one for the humid regions: In arid regions, the optimization process enlarges the soil water storage to an extent that enables the vegetation to hold as much water as possible, thus minimizing drought stress. Here, the stochastic precipitation is the only reason for the high scatter.

In summary, the optimization process for both cases adjusted the bucket size in such a way that the water availability is maximized throughout the year. Hence, the optimization of NPP led to a maximization of transpiration (with a given atmospheric demand).

\section{Sensitivity to increased water use efficiency}

For the two different setups of increased WUE (as described in the methodology section above) we optimized NPP again in respect to rooting depth. The global average of rooting depth is shown in Table 1 . In the '0.5*DEMAND' experiment, rooting depth was reduced in a rather uniform way in most regions (not shown, the patterns of change are very similar to those in changes in NPP, see below), while in the ' $2 *$ ALPHA' experiment rooting depth did not change for most regions except at the transition to desert regions, where it increased (not shown).

In the '0.5*DEMAND' experiment, global ANPP increased by $21 \%$ using the standard distribution $(D=$ $1 \mathrm{~m})$ and $16 \%$ in the presence of optimized rooting depth. In contrast to this, the increases in the ' $2 * \mathrm{ALPHA}^{\prime}$ experiment were lower with $5 \%$ and $10 \%$ for the standard and optimized rooting depth distribution, respectively (see Table 1). The patterns of ANPP increase were quite different: When using the standard rooting depth, ANPP increased mainly in regions with a distinct dry season and rather uniformly in both cases, with a larger magnitude of change for the '0.5*DEMAND' experiment (Fig. 3c). In contrast to this, the increases in ANPP for the optimized distribution reached peak values at the boundary to desert regions. Again, the pattern is similar for both cases, with higher magnitude for the '0.5*DEMAND' experiment (Fig. 3d). The annual average of global transpiration did not change in the ' $2 * \mathrm{ALPHA}^{\prime}$ experiment, while for it decreased in the ' $0.5^{*}$ DEMAND' experiment by $38 \%$ and $41 \%$ for the standard and optimized rooting depth distribution (Table 1).

\section{Discussion}

Deep roots have been found by field workers in many parts of the tropics (Stone \& Kalisz 1991), but have yet been neglected by the global modelling community. The results of our study suggests, that deep roots as suggested by the optimization process are important especially for tropical ecosystems, mainly because of two mechanisms: First, the increased soil water storage capacity induced by the deep roots supply sufficient water for the dry seasons. This removes the drought stress from the vegetation and consequently the productivity of those ecosystems with a drought period is substantially increased. Secondly, a larger soil water storage reacts more slowly and the productivity is less affected by climatic variations. Even though we used a simple model, these two mechanisms are not only inherent properties of this simple model, but rather fundamental. Hence, they are very likely to have similar impacts on more sophisticated models as well. They also suggest, that rooting depth should preferably be classified on a water-deficit basis and not on a biome basis.

In summary, vegetation with an optimized rooting depth distribution is less vulnerable. In fact, a (fixed) rooting depth of the order of $1 \mathrm{~m}$ can be seen as a region where the vegetation is not in equilibrium with its environment. This is the case, e.g. for deforestation (or general changes in land use). Considering the changes we described here resulting from an optimized rooting depth distribution, deforestation is likely to have much larger effects on climate and hydrology as previously thought (e.g. Henderson-Sellers et al. (1993), Nobre et al. (1991)). From this point of view, a vegetation without an optimized rooting depth distribution is more affected by climatic variations, experiences enhanced water stress during the dry season, evaporates less water and, consequently, runoff is increased. 
The stabilizing effect of optimized rooting depth can also be seen in the sensitivity experiments: The response in ANPP is much more dependent on the implementation of a doubled WUE in the presence of a standard rooting depth than for the optimized rooting depths. Since the optimization process reduces the extent of drought stressed vegetation and 'pushes' the limit towards desertlike environments, less areas are affected by an increased WUE. In fact, the response, in terms of ANPP changes, is concentrated only on regions where annual potential evapotranspiration exceeds precipitation. In areas of dry periods with no annual water deficit only the rooting depth estimates are affected by a modified WUE. The modification of rooting depth, however, can affect the carbon cycle within the soil. The impact of doubled WUE on the water cycle is strongly dependent on how it is implemented in both cases.

Further implications of the presence of deep roots cannot be investigated in the scope of this study, since we have a fixed climatic environment, which is given by observed distributions of the climatic parameters. A next step is to apply this method to a Atmospheric General Circulation model to study the impacts of enhanced (and less seasonal) fluxes of latent heat on the simulated climate.

\section{Limitations of the model}

Since we applied the method to a simple model, the results are subject to several limitations and should be taken as a demonstration of the method. We discuss the main limitations, how important they are and how they could be resolved in the following sections.

Net Primary Production. NPP is parameterized in a very simple way. It could be easily replaced by a more sophisticated model, which explicitly simulates processes like photosynthesis, nutrient cycling, phenology (such as budburst and leaf-shedding for temperate deciduous trees) and stomatal control. However, the main driving force in the maximization process was the water availability and not the productivity itself. Therefore it seems more reasonable to include a more realistic water uptake scheme. Since most present-day models of the terrestrial biosphere use hydrology schemes that are similar in its simplicity to the one used in this study, the distribution of optimum rooting depth calculated from these models and the impacts are probably comparable.

Vertical heteorogeneity of soil water distribution/groundwater. We used a simple model to simulate soil hydrology. Since the model consists of one soil layer only, impacts on rooting depth (and on the water stress factor) resulting from a heterogeneous vertical soil water distribution are ignored. The simulation of soil hydrology could be improved by increasing the vertical resolution, i.e. by the use of a multilayer model. This requires knowledge about the global distribution of soil and plant parameters that determine the fluxes between the soil layers and water uptake by roots. Other sources of water such as ground water or lateral transport by rivers are also not considered within the model. However, the estimates of optimum soil water storage patterns and the impacts on hydrology and NPP are unlikely to change substantially, since after all the main driving factor for optimum soil water storage was the atmospheric water deficit/surplus (see Fig. 6).

Bare soil evaporation. In this study it is assumed that the vegetation completely covers each grid point. In reality, water evaporates also from the soil directly. This effect becomes more important in arid regions, where the vegetation cover decreases. However, bare soil evaporation affects the top part of the soil column only and its impacts on the results of this study seems minor. In a multilayer soil hydrology model this process could easily be incorporated. In a bucket model, where soil water is simulated by one layer only, this process would likely to be overestimated in the presence of deep roots, since too much water from greater depths would be available for bare soil evaporation.

Bedrock/impermeable soil layers. Bedrock or the presence of an impermeable soil layer would also limit the development of a root system to some extent. Limitations by bedrock are likely to be present in mountainous regions. It is difficult to obtain the global distribution of impermeable soil layers but also how much the presence is limiting to root growth. For example, Lewis \& Burgy (1964) showed, that an oak stand extracted significant amounts of groundwater from the underlying fractured rock by roots going deeper than 20 meters (see also other examples in Stone \& Kalisz (1991)). If the depth of bedrock/impermeable layer were known, this could be used as an additional constraint for the maximization process. This, however, would not resolve the question of how limiting their presence is to the development of root systems.

Nutrient uptake. Nutrient uptake and its effect on NPP has not been implemented in the model either. We have seen earlier, that the maximization of NPP led also to a maximization of transpiration for most grid points. If we assume, that nutrients are taken up as ions that are dissolved in the soil water and nutrients are available at the same rate throughout the year, a maximum uptake of nutrients is also assured. Under this condition, nutrients are of minor importance for the estimation of rooting depth. If the availability of nutrients is out of phase with 
the demand of soil water (or the distribution is not constant with depth), the uptake of nutrients is not at a maximum. This would then require a more sophisticated model, where the formulation of NPP considers both, a water stress factor and a nutrient stress factor (which both might depend to some degree on the rooting depth).

Snow. Snowfall, accumulation and melt is not considered in the model. As already mentioned before, the neglection of these processes creates an artificial water deficit in some arctic regions. Incorporation of a snow module would eliminate this limitation; however, the results in this study do not indicate drastic changes in productivity or within the water cycle by the use of optimum soil water storage in the arctic regions. This is sensible, since these regions are more limited by temperature and light.

Frozen soil. Frozen soil sets a physical boundary for rooting depth. If the distribution of (maximum) thaw depth is known, it could be used as an additional constraint for the maximization process. This again affects arctic regions only and this limitation is unlikely to have a large impact on productivity or the water cycle.

\section{Limitations of the method}

While the limitations listed above result from the simplicity of the model and could easily resolved by the use of more sophisticated models, there are also limitations to the method itself, which are more serious.

Equilibrium of vegetation/potential vegetation. The optimization method assumes that the vegetation is in equilibrium with its environment, which is not necessarily the case even for natural vegetation. Surely, this method fails where mankind influences the presence of species, such as agricultural areas. We should therefore call the optimum rooting depth a 'potential' rooting depth.

Drought-avoidance strategy. In the way the method has been set up, it is assumed that in every grid cell evergreen vegetation is present and that it is subject to the atmospheric demand of transpiration throughout the year. In the real world, however, there are plants that simply shed leaves (or die) to avoid drought stress. This is the case for biomes such as grasslands and dry-deciduous forests. Probably this is one reason why the rooting depth is overestimated in the tropical deciduous forest biome, for shrubs and for the temperate grasslands. To incorporate leaf-shedding as a mechanism, it would be necessary to have an explicit representation of the carbon costs of root growth/water uptake, so that it can be evaluated whether it is 'worth' for the vegetation to develop deep root systems.
Optimal behaviour. We used an optimization approach in this study, which implies that the vegetation makes optimum use of its environment. This, to some degree, also implies that the vegetation can 'foresee' the future development of the climatic forcing. Nevertheless, since the model is not optimized at each time step but rather over a long time interval (10 years), the outcome of the optimization reflects an adaption of rooting depth to a mean climate only. It has been suggested (e.g. Reynolds \& Chen 1996) that plants allocate in a way ('coordination theory') where the imbalance between supply and demand of different plant variables (such as carbon and nitrogen) is reduced in each time step in contrast to an optimum behaviour. Applied to the problem of rooting depth, it would mean, that allocation would correct the imbalance between carbon and water supply. To do so, an explicit representation of carbon costs for water uptake is required.

\section{Summary and conclusion}

We have shown that applying an optimization principle to a simple biosphere model is capable of reproducing observed patterns of rooting depth. This way, the rooting depth distribution is consistent within the model (and its forcing) to the idea, that the vegetation has adapted to its environment and maximizes carbon gain. Evidently, larger rooting depths make the vegetation less vulnerable to day-to-day and seasonal fluctuations, which has large impacts on productivity and the hydrological cycle in tropical regions with a dry period. We have found, that the main driving force for deep roots within the optimization process is the water deficit during the dry season. Even though a simple soil hydrology model has been used, the increased soil water storages are likely to cause similar impacts in other global models of the terrestrial biosphere. The increased soil water storages and the associated increases in latent heat flux are likely to have a significant impact on the simulated climate within General Circulation Models. This in turn suggests that impacts on the climate and the hydrological cycle by deforestation might be stronger than previously thought.

\section{References}

Batjes NH (1996) Development of a world data set of soil water retention properties using pedotransfer rules. Geoderma, 71, 31-52.

Canadell J, Jackson RB, Ehleringer JR, Mooney HA, Sala OE, Schulze E-D (1996) Maximum rooting depth of vegetation types at the global scale. Oecologia, 108 (4), 583-595. 
Dickinson RE, Henderson-Sellers A, Kennedy PJ (1993) BiosphereAtmosphere Transfer Scheme (BATS) Version 1e as Coupled to the NCAR Community Climate Model. NCAR/TN-387, National Center for Atmospheric Research, Boulder, Co.

Dümenil L, Isele K, Liebscher H-J, Schröder U, Schumacher M, Wilke K (1993) Discharge Data from 50 Selected Rivers for GCM Validation. 100, Max-Planck-Institut für Meteorologie, Hamburg.

Dunne KA, Willmott CJ (1996) Global distribution of plantextractable water capacity of soil. International Journal of Climatology, 16, 841-859.

Federer CA (1982) Transpirational supply and demand: plant, soil, and atmospheric effects evaluated by simulation. Water Resources Research, 18, 355-362.

Friend AD (1996) Parameterisation of a global daily weather generator for terrestrial ecosystem and biogeochemical modelling. Ecological Modelling, in press

Geng S, Penning de Vries FWT, Supit I (1986) A simple method for generating daily rainfall data. Agricultural and Forest Meteorology, 36, 363-376.

Heimann M, Keeling CD (1989) A three-dimensional model of atmospheric $\mathrm{CO}_{2}$ transport based on observed winds: 2 . Model description and simulated tracer experiments. AGU Monographs, 55, 237-275.

Henderson-Sellers A, Dickinson RE, Durbridge TB, Kennedy PJ, McGuffie K, Pitman AJ (1993) Tropical Deforestration: Modeling Local- To Regional-Scale Climate Change. Journal of Geophysical Research, 98 (D4), 7289-7315.

Kaduk J, Heimann M (1996) A prognostic phenology scheme for global terrestrial carbon cycle models. Climate Research, 6, 1-19.

Kleidon A, Heimann M (1996) Simulating root carbon storage with a coupled carbon-water cycle root model. Physics and Chemistry of the Earth, 21 (5-6), 499-502.

Kleidon A, Heimann M (1997) Optimised rooting depth and its impacts on the simulated climate of an Atmospheric General Circulation Model. Geophysical Research Letters, submitted.

Leemans R, Cramer W (1991) The IIASA Climate Database for Mean Monthly Values of Temperature, Precipitation and Cloudiness on a Terrestrial Grid. RR-91-18, Institute of Applied Systems Analysis, Laxenburg/Austria.

Lewis DC, Burgy RH (1964) The relationship between oak tree roots and groundwater in fractured rock as determined by tritium tracing. Journal of Geophysical Research, 69 (12), 2579-2588.

Linacre ET (1968) Estimating the net-radiation flux. Agricultural Meteorology, 5, 49-63.

McNaughton KG, Jarvis PG (1983) Predicting the effects of vegetation change on transpiration and evaporation. In: Water Deficit and Plant Growth (ed. Kozlowski TT), pp.1-47. Academic Press, New York.

Mooney HA, Drake BG, Luxmoore RJ, Oechel WC, Pitelka LF (1991) Predicting ecosystem responses to elevated $\mathrm{CO}_{2}$ concentrations. BioScience, 41 (2), 96-104.

Nepstad DC, de Carvalho CR, Davidson EA, Jipp PH, Lefebvre PA, Negreiros HG, da Silva ED, Stone TA, Trumbore SE, Vieira $S$ (1994) The role of deep roots in the hydrological and carbon cycles of Amazonian forests and pastures. Nature, 372, 666-669.

Nobre CA, Sellers PJ, Shukla J (1991) Amazonian Deforestration and Regional Climate Change. Journal of Climate, 4, 957-988.

Potter CS, Randerson JT, Field CB, Matson PA, Vitousek PM, Mooney HA, Klooster SA (1993) Terrestrial ecosystem production: A process model based on global satellite and surface data. Global Biogeochemical Cycles, 7 (4), 811-841.

Prentice IC, Sykes MT, Cramer W (1993) A simulation model for the transient effects of climate change on forest landscapes. Ecological Modelling, 65, 51-70.

Press WH, Teukolsky SA, Vetterling WT, Flannery BP (1992) Numerical Recipes in FORTRAN. the Art of Scientific Computing. Cambridge University Press, Cambridge.

Raich JW, Rastetter EB, Melillo JM, Kicklighter DW, Steudler PA, Peterson BJ, Grace AL, Moore IIIB, Vörösmarty CJ (1991) Potential net primary productivity in South America: Application of a global model. Ecological Applications, 1(4), 399-429.

Reynolds JF, Chen J (1996) Modelling whole-plant allocation in relation to carbon and nitrogen supply: Coordination versus optimization: Optinion. Plant and Soil, 185, 65-74.

Roeckner E, Arpe K, Bengtsson L, Christoph M, Claussen M, Dümenil L, Esch M, Giorgetta M, Schlese U, Schulzweida U (1996) The Atmospheric General Circulation Model ECHAM-4: Model Description and Simulation of Present-Day Climate. 218. Max-Planck-Institut für Meteorologie, Hamburg, Germany.

Sellers PJ, Randall DA, Collatz GJ, Berry JA, Field CB, Dazlich DA, Zhang C, Colello GD, Bounoua L (1996) A revised land surface parameterization (SiB2) for atmospheric GCMs. Part I: Model Formulation. Journal of Climatology, 9, 676-705.

Stone EL, Kalisz PJ (1991) On the maximum extent of tree roots. Forestry and Ecological Management, 46, 59-102.

Webb RS, Rosenzweig CE, Levine ER (1991) A Global Data Set of Soil Particle Size Properties. Digital raster data on 1-degree geographic $180^{\circ} 360^{\circ}$ grid. New York, NASA Goddard Institute of Space Studies.

Wilson MF, Henderson Sellers A (1985) A global archive of land cover and soil data for use in general circulation models. Journal of Climatology, 5, 119-143. 